\title{
Drawing a Line: Strictness and Consistency in the Dietary Habits of Ethically Motivated Vegetarians
}

\author{
Malcolm $\mathrm{H}^{*}$ \\ Department of Sociology, Senior Lecturer, University of Reading, United Kingdom \\ *Corresponding author: Malcolm Hamilton, Department of Sociology, Senior \\ Lecturer, University of Reading, 30 Melrose Avenue, Earley, Reading, RG6 7BN, \\ United Kingdom, Tel: 01189268461; Email: flyspot15@gmail.com
}

\section{Research Article}

Volume 3 Issue 1

Received Date: January 08, 2018

Published Date: March 24, 2018

\begin{abstract}
Drawing a Line: Strictness and Consistency in the Dietary Habits of Ethically Motivated Vegetarians Abstract the degree of strictness with which vegetarians maintain their diet often seems difficult to understand, especially in the case of vegetarianism motivated by ethical concerns. Refusal of food containing meat when offered by a host, avoidance of such things as gelatin and rennet, and so on, cannot have any effect upon the slaughter of animals. On the other hand the use of leather for shoes by most vegetarians seems inconsistent with such avoidances. This article report's findings from a study using in-depth interviews with vegetarians variously motivated by ethical as well as health and other concerns which explores these apparent inconsistencies and helps to explain them. Ethical vegetarianism, like most ethical stances, is difficult to follow fully in all its implications and consequences. A line has to be drawn beyond which vegetarians feel they ought to not reasonably be expected to go. This line is roughly drawn between ingestion of animal products and external use of them, firstly because this provides a clear and logical divide, and secondly because it is in any case associated with emotions of disgust and repugnance in relations to meat which typically develops in most ethically motivated vegetarians.
\end{abstract}

Keywords: Vegetarianism; Veganism; Meat; Ethics; Food Avoidances; Animal Products; Religion; Disgust

\section{Introduction}

Adoption of a vegetarian diet inevitably imposes dilemmas for those that do so, especially if their motive is predominantly ethical. There is the dilemma of avoiding or not avoiding the use of leather products - particularly difficult in the case of shoes. Vegetarians are sometimes quite strict about avoiding meat derived products such as gelatine and rennet. Many are aware of the fact that the production of dairy products involves the killing of male calves and feel they ought to avoid consumption of such products; taking the vegan path is, however, something that most cannot contemplate or, if they try it, sustain. Many never attempt to become vegan and accept that their vegetarianism inevitably involves contradictions with which they just have to live. Once vegetarianism has been adopted many such dilemmas confront the vegetarian [1]. 


\section{Food Science and Nutrition Technology}

As a result, non-vegetarians often find it difficult to understand the particularities of the dietary practices of vegetarians. If it is wrong to take the life of a cow for its meat why is not wrong to do so for its skin. Vegetarians are sometimes taunted by non-vegetarians about this and often have a difficult time justifying it and dealing with such challenges the more so, as the data discussed below shows, when they find it difficult to justify their actions to themselves. Vegetarians are confronted with the dilemma of where exactly to draw the line.

If vegetarians sometimes do not avoid eating or using animal products which their ethical stance might seem to require them to avoid, in other circumstances they often do avoid consuming them when it might reasonably be argued that there are no compelling reasons for doing so. There are circumstances in which it is difficult for vegetarians to avoid eating meat. When invited to dinner or at an important function it is often very embarrassing to have to refuse a meal containing meat when offered by hosts who do not realise that the guest is vegetarian. In such circumstances, some vegetarians will politely eat the meal while others will eat only the vegetables and leave the meat. Where it is not possible to separate the meat from the rest - if the meal is a casserole or something similar - while some vegetarians will, again, grit their teeth and eat it, others will simply not eat any of the meal at all despite the embarrassment it may cause. But why not eat the meal? It can make no difference. The animal is already dead, butchered and the meat prepared and cooked. Why, then, should some vegetarians be so punctilious? The assumption is, of course, that meat is avoided by ethically motivated vegetarians because they do not wish to contribute to the practice of animal slaughter or to the rearing of animals in what is considered to be inhumane conditions. Refusal of a meal containing meat would not appear too necessary since it cannot in any way implicate the guest in such practices. This is all the more so when contrasted with the fact that many vegetarians confess to backsliding and occasional consumption of meat [2]. We should not, perhaps, expect vegetarians any more than anyone else always to be perfect in observing the rules of behaviour they have adopted or accept as binding upon them, whether dietary or otherwise; we all fall victim to temptation at times. But why then should it be so important to refuse meat even though it may cause embarrassment and risk offending a host?

These dilemmas and variations in vegetarian practice suggest, perhaps, that there may be much more going on which might explain such behaviour. But what is it that is going on? A recent study carried out by the author throws some light on the question of the degree of strictness with which vegetarians maintain their diet and the processes which underlie the ways in which they seek to resolve or manage the dilemmas that arise from the vegetarian lifestyle.

\section{Methods}

The aims of this study were to investigate, using indepth interview techniques, a range of attitudes and beliefs of vegetarians concerning their dietary practices, to meat and also various aspects of their broader beliefs and ideas relevant to their vegetarianism. For purposes of comparison a sample of regular meat eaters was also interviewed.

An opportunistic/snowball sample of 47 vegetarians, including some vegans, and 19 meat eaters were interviewed and the interviews recorded. The vegetarian sample included 1 fruitarian, 2 vegans, 30 lacto-ovo vegetarians, 2 lacto vegetarians, 10 fish eating 'vegetarians'(1), and two lapsed lacto-ovo vegetarians one of whom subsequently eliminated red meat from her diet. There were 18 men and 28 women from 15 to 65 in age with the modal age in the 41-50 range. They had been vegetarian from 3 to 56 years. They were predominantly well educated and middle class. While motives were often multiple, 17 had originally adopted vegetarianism (or veganism) primarily for ethical reasons (either killing or treatment of animals or both), 10 primarily for reasons of health, 6 for both health and ethical reasons about equally, 5 primarily due to a dislike of meat and 5 primarily for other reasons. Four had been brought up vegetarian.

Previous research has shown that when a vegetarian diet is adopted from a particular motive it is not unusual for further reasons to be added later on $[1,3,4]$. This was the case with the sample used in this study. A large proportion had changed their motives either adding to or replacing their original motive. Twelve respondents (seven lacto-ovo/vegan/fruitarian and five fish eating) stated no change of motive over time. Sixteen (fifteen lacto-ovo and one fish eating had added motives to their original motive(2). Six (three each of lactoovo/vegan/fruitarian and of fish eaters) had dropped an original motive. Three (all lacto-ovo) had both added one or more new motives and dropped others. Eight (seven lacto-ovo/vegan/fruitarian and one fish eating) had dropped their original motive(s) and acquired entirely new ones(3). Motives added and subtracted varied greatly. Very often health oriented vegetarians had come to accept the ethical arguments against eating meat or had simply 


\section{Food Science and Nutrition Technology}

come to dislike it. Some of those originally motivated by ethical considerations had since changed their views about this but had come to believe that a vegetarian diet was healthier or, again, had developed a dislike of meat. Some simply retained the vegetarian diet from sheer habit. The picture is, therefore, quite a complex one.

Apart from those who had been brought up vegetarian all had previously eaten meat, in most cases extensively, and the majority had liked and enjoyed many, if not all, types of meat before becoming vegetarian. Some had never really liked or enjoyed it much and for them adopting a vegetarian diet was no sacrifice at all. Most were very or fairly strict about conforming to their diet. A few were rather lax in this respect either eating meat on occasions or not taking care to avoid meat derivates such as gelatine, animal fats and rennet.

Meat consumers were very similar to the vegetarians in educational background and class position; 13 were male and 9 female. They were somewhat more evenly spread with regard to age. High proportions were keen meat eaters consuming substantial amounts.

The length of interviews ranged between 30 and 90 minutes averaging for vegetarians about 60 minutes and for meat eaters about 40 minutes. Vegetarians were asked about their motives for avoiding meat, whether these had changed over time, how they originally became vegetarian and so on. They were asked whether they were ever tempted to eat meat, whether they ever did so and about their consumption of meat products and derivatives. The main products which are relevant in this respect are gelatine, rennet and leather. They were asked how carefully these products were avoided, for example, by checking labels for the ingredients in food products. In addition to their attitudes to and feelings about meat generally they were asked about situations of exposure to meat they had experienced or what they thought their reactions might be should they encounter such situations. These included being given a meal containing meat, inadvertent ingestion of meat, having to purchase or handle meat, entering or seeing into a butcher's shop and so on. They were asked about their feelings regarding particular forms of meat, cuts of meat, type of animal etc. Also, they were asked about their views on a number of issues relating to the taking of life, violence and aggression; nuclear weapons, capital punishment, boxing, abortion, fox hunting, shooting, angling and fishing for sport and the genetic modification and use of animals for 'spare parts surgery', environmentalism and biotechnology which relate to research questions other than those with this article is concerned.

\section{Results}

\section{Rejection}

When asked whether they would eat or refuse a meal containing meat in social circumstance where it was very difficult and embarrassing to do so nearly every respondent said they would refuse to eat the meal.

One or two said they might find the social embarrassment too much to cope with and make themselves eat what was offered to them. One respondent who had lived for a time in Spain explained that there it was so rude to refuse food that she felt constrained to eat meat on occasions. Another respondent who had lapsed, for a variety of reasons, from lacto-ovo vegetarianism to eating fish reported a situation while traveling in the United States where social pressures overrode principles and partly precipitated the lapse into fish eating.

In circumstances such as these, however, most respondents said they would not eat the food or eat only those parts of the meal that was not meat even if this would cause considerable embarrassment. For some it was virtually impossible for them to eat the meat.

I just find the idea of eating a dead animal just horrible. Even to be polite socially I just couldn't do it. If I went round to somebody's for dinner and they didn't know I was vegetarian I could force my way through an omelette or something but I couldn't eat a sausage or a steak. I just couldn't. I would have to say look I'm sorry but I just can't eat this. (SB1)

I wouldn't no, no, um, um, I don't think in any circumstance I'd eat meat out of politeness or courtesy, um, and I always sort of make the effort to tell people that I am vegetarian before I - sort of you know to try and pre-empt that situation but, um, if that situation arises, I mean I wouldn't have any qualms about, you know, just eating nothing rather than eating meat if that's the only thing on offer. (SB6)

\section{Ingestion}

Respondents were asked about their feelings and reactions to occasions when they had actually if inadvertently eaten meat or how they might feel if they were to discover shortly afterwards that they had eaten something containing meat. A considerable proportion of the sample, about 15 respondents, expressed negative feelings about such an experience or the thought of it. These ranged from unease, anxiety, anger and guilt, through contamination and harm to unease, discomfort, 


\section{Food Science and Nutrition Technology}

queasiness, deep revulsion and even sickness as the following series of quotes illustrates.

I'd be a pissed off, actually, that, um, that sort of thing had happened. But I wouldn't make myself sick or anything. I'd just be a bit annoyed with myself. (SB2)

I think I'm more extreme in my reactions now than I would have been. I think initially it would have been the losing face aspect of it because "I'm vegetarian" whereas now although that's still important to me it shouldn't be. What's important is the health and the moral thing not what labels are; that's not important. (SB1)

I think it would feel like a poison and maybe my system wouldn't cope with it. (LC2)

....I would probably feel a bit unclean for a couple of days. I might go on a fruit diet for a couple of days to clean myself out. (SB1)

Yes, um but I am fairly convinced that if I did knowingly well if I actually forced myself to eat the stuff I'd probably throw it up immediately; that's for sure. (SB11)

No health oriented vegetarians reported such feelings resulting from ingestion of meat. A few said that they had experienced or thought they would experience mild feelings of anxiety or some discomfort. On the whole these were related to digestive concerns.

\section{Disgust and Repugnance}

It is not just the idea of ingesting meat that elicits feelings of disgust and repulsion from many vegetarians. It has been reported in a number of studies that meat as a substance in itself, particularly when seen raw, is felt by vegetarians to be deeply repugnant $[1,3,5,6]$. In the present study it was felt to be highly or moderately repugnant by most of the originally ethically motivated vegetarians (12 out of 17)(4). Expressions of repugnance were in many cases quite strident and intense. Those originally motivated primarily by health concerns were much less likely to find meat repulsive. Only one expressed such feelings fairly strongly and another to a moderate degree. In the first of these instances an ethical dimension to the motivation had emerged over time accompanied by a growing sense of aversion to meat and feelings of revulsion towards it. In a third case - a fish eating 'vegetarian' - the respondent had grown up not eating red meat at all and had an aversion to eating it before deciding to drop other forms of meat from her diet. Her avoidance of red meat was associated also with a rather vague sense of sympathy for animals of a certain kind - in effect, mammals such as cows and pigs - and, therefore, mildly ethical.

In another case of non-ethically motivated vegetarianism where the development of a strong aversion to meat was reported, the respondent had adopted a vegetarian diet for the sake of convenience. Where the original motivation was dislike of meat, it was generally regarded as repugnant as it was in the case of the four respondents who had been brought up vegetarian. Three of them, in any case, came to accept the ethical arguments against eating meat when they became adult.

The development of aversion to meat and feelings of repugnance, then, was not something that all ethically motivated vegetarians neither experienced nor was it exclusively confined to them; but it did characterise most of them and it was virtually absent or very weak among health motivated vegetarians. It was also typical of those motivated by dislike of meat, as one might, perhaps, expect even if dislike of the taste or texture of meat does not necessarily mean that it is seen as disgusting.

Those who felt repulsed by meat often mentioned the sight of it in butcher's shops or supermarkets. One lactoovo vegetarian initially motivated by ethical and environmental reasons stated.

I think, I mean if I sort of walk past the butcher's or supermarket with raw meat on sale there's something about it that looks really nasty and because - I think, what I, I think, I regard it as dead - sort of dead flesh really and which of course it is, and there's something, you know, it just sort of looks morbid and I think is that purification or? but I know it's not. I know it's not putrefying but it still has that sort of feeling about it and I do sometimes think well could I put that into my mouth and into my body and then I know that I couldn't do, because it just would be - it would be just - that physical act would be just too horrible.(LC1)

One respondent when asked why she looked away when passing butchers' shops said: Dripping bits of dead flesh and well occasionally you - especially when you've got small children who are wandering around, and your shopping and there's a real bit of body hanging in a window by a hook. That's horrible. I don't know how anyone would really be comfortable with it. (SB18)

Another likened the meat in a butcher's shop to human flesh: Um, I think it's, it's very unpleasant to have to have to look at it really and see carcasses hanging up in 


\section{Food Science and Nutrition Technology}

butchers, you know, in plain display, 'cos basically if you chopped up a human that's what it would look like, and if you could eat human meat it would be very similar.(SB19)

This association between meat and human flesh was quite frequently made among respondents: Well you wouldn't really want a dead person lying on a table, so what's the difference between a dead person and a dead animal.

\section{Interviewer}

You think they're the same, much the same thing?

Respondent

Well they are when you get down to it. (SB20)

No, it's not the meat itself, it's, it's a dead animal, it's a dead thing, it's a thing that's been killed and there it is, it's like seeing someone on a gibbet or something. (SB23)

The development of a disgust reaction to meat was, however, not something exclusive to ethically motivated vegetarians, as stated above. One respondent who had adopted a vegetarian diet for reasons of convenience her husband had adopted a vegetarian diet for health reasons and she found it simply more convenient to cook and eat the same food as he - found that she developed an aversion to meat after about a year or so.

We didn't eat any meat at all from then on and within, I think, a year or so I just had an aversion to meat. I couldn't handle it; now I can't handle it. I can't smell it. Red meat especially I find very repulsive. I can't walk by a butcher's. I can't bear the smell of it in the kitchen - um cooking in the kitchen at all. (SB3)

The intensity of disgust felt by many ethically motivated vegetarians leads them to take avoidance actions of various sorts such as crossing the road in order not to have to walk past a butcher's shop window or taking a long detour around the supermarket isles in order to avoid walking past the cabinets containing meat.

For example one lacto-ovo vegetarian on the way to adopting veganism reported: The supermarket that I normally shop in it's not possible to walk round without getting fairly close to where the meat is. Although I do walk partway down the aisle to what I want because a lot of the meat substitute products are next to the meat. So I walk down to the meat substitute products and then I walk back up the aisle rather than go down past the meat. So I do as far as I can avoid walking past it; I think more for the smell than the visual thing but I find both quite horrid and I do wish they had a separate section. Butchers' shops one doesn't come across in the way one used to. I do wish they had concealed windows like sex shops do so I don't really know what's going on in there. (SB1)

Even an association with meat can make something or someone repulsive. The lacto-ovo vegetarian attempting to become vegan quoted above expressed this in a very striking way referring to her husband who was also close to adopting a fully vegan diet.

If one we were suddenly to decide to become carnivore I think that would be a very significant strain on our relationship. ...I would actually find it very difficult to have a physical relationship with a carnivore which is perhaps taking the disgust side of meat a little far but nevertheless that's how strongly I feel about it.

It is significant that such feelings and behaviour persist after initial ethical motivations have diminished or been relinquished. Interestingly, in the cases of two lapsed vegetarians such feelings of repulsion disappeared when they returned to eating meat. One ethically motivated respondent returned to eating meat at her husband's instigation. He had gone along with the vegetarianism but covertly did not share her convictions and did not enjoy the diet. On announcing that he wished to return to having meat in his diet she also decided to give up her vegetarianism and found that her feelings of revulsion evaporated.

Many vegetarian respondents reported that they felt unable to eat meat and repulsed by the sight of it more or less as soon as the decision to become vegetarian was taken. For others aversion to meat and feelings of repugnance associated with it developed over time, sometimes almost imperceptibly so that it was impossible for them identify any particular point in time when such an aversion had taken hold.

It was quite common that such reactions to meat were suddenly noticed when unexpectedly confronted with meat. One respondent replied when asked about the development of such feelings:

Slowly over the course of several years. I only really start to notice it when I pass a butcher's shop and I think ugghh, no not nice. (VM3)

It may be that there is a tendency for feelings of disgust to be of greater intensity to the extent that the ethical concern is greater. One respondent who had adopted veganism after many years as a lacto-ovo vegetarian 


\section{Food Science and Nutrition Technology}

reported the following in relation to his feelings of revulsion:

It probably got worse since becoming a vegan. It's harder to cope with now than it was twenty years ago when I just getting into being a vegetarian. (LC4)

Another respondent who was moving increasingly towards a vegan diet when asked about any possible relationship between her ethical stance and her feelings of revulsion stated:

Yes I think they are related. The more I think that it's morally wrong to eat meat the more it seems disgusting to do it. (SB1)

\section{Strictness in Avoiding Animal Products}

A number of other studies have shown that while many vegetarians are revolted by the idea of eating meat some vegetarians are not, are sometimes tempted to eat it and sometimes do eat it. Willetts (1997) [2] reports of her south London study that 66 per cent of the self-reported vegetarians in the survey consumed meat on occasions(5). In the present study there was a clear difference between healths oriented vegetarians and ethically oriented vegetarians in this respect. Ethically oriented vegetarians hardly ever ate meat while a few health oriented vegetarians did so occasionally or were sometimes tempted to do so.

There was much more variation in the extent to which vegetarians in the study avoided meat products and derivatives in food. The most important examples are animal fat derived from meat rather than dairy products, gelatine which is an ingredient in many products, and rennet which is used in making cheese. Respondents were asked about how punctilious they were in avoiding foods containing these substances. Apart from food itself another animal product which many vegetarians feel should be avoided is leather since its production involves the slaughter of animals as much as does the production of meat, meat derivatives and other animal products.

The degree of strictness with which vegetarians followed their diets sometimes changed over time. Quite a few respondents reported that in the earlier days immediately after adopting a vegetarian diet they were unaware that many food products contained substances of animal origin. From reading books and magazines about vegetarianism they learned about this as time passed and, consequently, learned to check labels for the ingredients of the foods they bought. Many reported that they were very punctilious in doing this. Some relied heavily on food bought in health food shops, which they knew would not contain substances derived from animal sources other than dairy (or at all if they were vegan), or which were clearly marked with the symbol indicating suitable for vegetarians. Others said that having established a fairly fixed pattern of food purchases they no longer needed to check labels in order to be confident that no meat derivatives were present in the food.

A few respondents reported that in the early days after adopting their new diet in the full flush of enthusiasm they had been very strict but that over time they had become a little more relaxed about it, not always bothering to check labels. Although practices differed somewhat from one individual to another, generally speaking most reported a degree of care in avoiding substances of animal origin other than dairy products but because of the time, effort and difficulty involved in always being certain of this many stopped short of what they often described as fanaticism in this respect. For example, in restaurants they did not always ask if certain dishes might be made using ingredients containing gelatine or with non-vegetarian cheese. When dining with friends they did not ask if cakes and biscuits had been made using some animal fat. In some cases they could not help consuming favourite things such as chocolate even though they knew they were likely to contain some gelatine. Often a blind eye was turned to this possibility. Several respondents reported that they would eat such things provided that they did not know that they contained gelatine but would not eat them if they knew them to do so while acknowledging that they would not always or usually take steps to find out.

Bearing these nuances in mind, the general picture regarding the relationship between different types of diet and strictness was that vegans and lacto-ovo vegetarians tended to be more strict than those who ate fish. A large majority of lacto-ovo vegetarians and vegans were strict in avoiding all of these products while fish eating 'vegetarians' were less often so. In addition to the avoidance of foods containing any kind of meat or meat extract, a good measure of strictness is the extent to which products containing gelatine and animal rennet are avoided. Defining strictness as avoidance of both of these and laxity as consumption of, or lack of concern about consumption of, both of them, fish eating 'vegetarians' were evenly spread between those avoiding both, those avoiding one or the other and those who consumed both or who, while avoiding them to some extent were unconcerned about consuming them and who made little attempt to ensure they did not do so. Most lacto-ovo 


\section{Food Science and Nutrition Technology}

vegetarians avoided both while only handfuls consumed or were unconcerned about consuming both.

Just as ethically oriented vegetarians tended to be more consistently strict in avoiding consumption of meat they were similar so in avoiding animal products in food than health oriented vegetarians. Most reported a high degree of vigilance in avoiding foods with any kind of meat derivative or extract such as lard and other forms of animal fat other than dairy products. Almost all ethically oriented vegetarians reported they were vigilant in avoiding either one of or both gelatine and rennet with about half being careful to avoid both. Health oriented vegetarians were more polarised in this respect and largely divided between those who were strict and those who were rather lax. All of those whose motives were a mixture of health and ethical concerns reported that they were careful not to consume either rennet or gelatine which suggests that the addition of an ethical dimension to their health concerns makes them particularly vigilant in this respect. Several respondents mentioned the issue of BSE and how this had heightened their awareness of the use of gelatine in a variety of products and had made them more vigilant in avoiding them. While not the only ones to mention this, some of the health motivated vegetarians were particularly worried about the issue of BSE which had played a major part in their decision to become vegetarian. While only affecting beef these respondents felt that it was safer simply to cut all meat from their diet having lost confidence in the safety of meat in general.

\section{Leather}

Very few ethically motivated vegetarian respondents reported that they avoided leather products, especially shoes. Some respondents justified this in terms of leather being a bi-product of meat production and, therefore, the use of it not contributing to the killing of animals.

I just suppose it's a bit hypocritical but, um, but because it's not - I suppose at heart it's not an ethical thing, um, but also I do have a sort of - and perhaps it's a cop out in saying it - but if animals have died then you might as well use the products from them and say if other people have killed them for meat then we might as well use their hides to make our shoes. But um, I suppose that's a bit tenuous really isn't it.(SB15)

Uh, I wear leather because, um, I try not to buy brand new leather coats and things. I get second hand or ... I do wear leather shoes because of the environmental issue; it's bio-degradable. I think, I may as well wear it. Also it's like the waste issue; you know, the animals are being eaten so you may as well use the leather and get something out of it, so it's kind of it's like that, yeah. I'm not worried about leather really, and I mean only where it's a waste....(LC1)

The eating of the flesh that - I mean once you have killed the animal, the skin doesn't seem to be the major issue; you know you kill it to eat it and whatever's left they use.(SB8)

While they may express a certain degree of embarrassment and guilt about using leather products, few respondents reveal any strong inclination to avoid them. When confronted by critics of their vegetarianism on the contradiction this seems to entail, which they quite often are, they have no satisfactory answer and express little or no real and effective motivation to see their convictions through and remove the contradiction. A few do try to avoid leather products, even shoes, usually failing to do so fully, but most do not even attempt to do so, seemingly content to live with the contradiction. When asked about the issue of leather one respondent replied:

Yeah, I have thought about that. I do still wear leather. Um, which I mean - it's just hypocritical really I suppose. But I don't know, it's something about not putting it in your mouth somehow. I don't know really; there's not really a logical reason why I don't eat meat and I do wear leather because they are both equally unnecessary but, um, it doesn't repulse me in the same way as the thought of eating meat does.(SB10)

A fish eating 'vegetarian' when asked if she avoided leather goods replied:

Well only if - with the shock that I ought to. I thought Oh goodness. Um, I probably wouldn't buy leather and that's fine as plastic is nearly always cheaper anyway. But having said that I bought shoes without looking and found that they are in fact leather and I will wear them. I realise that that is hypocrisy as well. It goes with fish and I'm not as pure as pure on this one at all, I'm afraid. But I - if you said to me, um, leather or plastic, I would say plastic, if you give me the choice but I don't always remember to look if I'm buying something. (SB36)

\section{Discussion}

\section{Observance}

The rules that vegetarians, especially ethically motivated vegetarians set for themselves with regard to the use and consumption of meat and animal products which they observe with varying degrees of punctiliousness are, in many ways, reminiscent of the 


\section{Food Science and Nutrition Technology}

rules and observances associated with religion. Religions throughout the world impose certain disciplines and observances upon their followers and these often involve dietary practices. The Jewish dietary law is the most obvious example. Vegetarianism also could be seen as a form of self-discipline and set of observances that expresses the identity of the practitioner and his or her moral standing. In some ways, the dietary abstentions of the vegetarian might express his or her apartness and distinctiveness as the dietary taboos of Jews and followers of other faiths often do. As with religious observance, which in certain cases and contexts tends to become elaborated and extended to encompass an ever more precise and strict set of rules of avoidance, so also with vegetarians the rules concerning what can and cannot be consumed tend towards increased refinement. New situations and circumstance arise which raise questions about the ethicality of consuming certain products; windows of opportunity and obligation open up during the development of the vegetarian lifestyle [4]. Most find it too constraining to take up these opportunities or fulfill these obligations and fail to do so, with varying degrees of guilt and feelings of hypocrisy. Some pursue them to varying lengths, in some cases all the way to veganism or even to a highly sectarian fruitarianism.

An attraction of religious and political sectarianism, it has been argued [7], is that it sets the few apart from the mass and gives them, in their own eyes, a special status and a distinct and special identity. It has been argued that for vegetarians also there may be a particular gratification which stems from being different from others and/or morally superior. They are, through their diet, a select group reminiscent of O'Toole's Maoists and De Leonists who derived satisfaction from knowing that only they were in possession of a true understanding. According to this view there is a sectarian tinge to vegetarianism. The concern to be among the select is demonstrated in the hierarchy of status and prestige that seems to obtain between vegetarians, vegans and at the very top fruitarians, reflecting the hierarchy of foods themselves defined by Twigg $(1983)[8,9,10]$ in terms of a reversal of the status these foods have in the dominant meat-eating culture.

The interview data bear out to some extent the claim that vegetarians feel and see themselves as different from the majority as a result of their vegetarianism. Fifteen reported that they clearly did so and another half dozen or so felt this rather more slightly or equivocally. It is also the case that this was for most a positive feeling. Fourteen said it was a positive feeling while only six found it to be negative.
It is less clear that such feelings were associated with a sense of superiority or of being special. Most respondents were very hesitant about claiming superior status due to their ethical stance and dietary practices. A few did so, however. One respondent whose original motive had been largely ecological and associated with political radicalism and antagonism to Western capitalist modes of food production, speaking of the time he became a vegetarian said(6):

Um, I think it was all the process which went on, possibly over a year or 18 months, - was all part of that establishing our identity at the time and I remember that it was, um, it was discussed quite a lot with friends who we saw on a regular basis, um, and talked about all sorts of things, and yes it was part of the way that we identified ourselves. Some of our friends were also becoming vegetarians in a very similar way and others were very resistant to the fact, and to others it was very shocking that we should be becoming vegetarians and they were probably people that we enjoyed shocking and that was part of almost the fun of the process. Also, we were in our early twenties. The fact that it was so shocking to our parents, especially my wife's parents who come from a French tradition, was part of the fun of becoming a vegetarian as well...... I was a quite combative person in those days and I enjoyed that. I enjoyed the idea of shocking the bourgeoisie and shocking the generation of my parents and so on. It was, um, there were all sorts of practical difficulties about being a vegetarian particularly if somebody had traveled a lot, um but, um, I actually welcomed the challenge of being different in that way.(SB9)

Others were less concerned with the political dimension but took pride in standing out as people who had strong moral convictions which they upheld through their lifestyle. When asked whether the feelings of difference she experienced were positive or negative one respondent replied:

Um, for me it was positive, and I was quite, I was suppose I always have $a$ - I think at that time I was quite sort of proud of being vegetarian, 'cos you had to work at it really, um. I'm proud now as well.......'cos I feel it's the right thing to do, you know. Um, as I say, it's a - in a way it's a statement; it is a statement. (FC2)

And another said:

I am arrogant enough to say that it makes me feel holier than thou sometimes, like hey, wow, you know score ten points for me. (VM2) 


\section{Food Science and Nutrition Technology}

A feeling of solidarity with other vegetarians and a sense of belonging to a distinct group or fraternity was expressed by another respondent.

Um, it does make me feel as if you are a part of a sort of a club almost that, um, that if you are at something and you meet people that you don't know at all - if you, if you find out that two of you are vegetarians there's a sort of instant, um, - I'm not saying that you automatically get on with them - but there's like a an instant sort of um interest, I suppose, between you and a bond and sort of - and you sort of always feel pleased when someone else is. (SB15)

Apart from these four respondents feelings of difference were reported to arise from such things as simply not being able to eat the same dishes as others in restaurants, being challenged by others about their vegetarianism and having to defend it or just the awareness or expectation that others would perceive them as different. For quite a few, as stated above, this was mildly problematic and negative but for many it was interpreted in a positive way, yielding feelings ranging from moral superiority through personal virtue or righteousness to distinctiveness and rebellion.

There is, then, clearly some support for the view that sees vegetarianism as having a sectarian dimension although this should not be exaggerated and many vegetarians dislike feeling different and reject the idea that it makes them in any way different let alone morally superior.

A noticeable feature of much vegetarian practice revealed by the interview data which strengthens the impression of it having a 'sectarian' dimension is the tendency to become very sensitive to the rules of the diet and punctilious about observing them beyond what seems necessary to achieve ostensible aims. The example of refusing meat served by a host mentioned above is relevant here. Another tendency of this kind is to elaborate and expand the rules of observance to accommodate new circumstances that come into awareness. Consumption of dairy products, for example,

may be relinquished when it is realised that their production involves the slaughter of unwanted animals, their mistreatment in factory farming and so on. There is often, then, a compulsion towards adoption of a vegan diet which, however, most find impossible actually to accomplish. Observances may extend, also, beyond diet as in the case of avoiding wearing leather shoes or garments (and, of course, fur) or there is, as we have seen in the interview data, often a sense of guilt and an anxiety about hypocrisythat while this should be observed it cannot easily be in practice. There is more than a hint of sin in such concerns and practices and of a sense that we cannot avoid 'sinning' a little or live an entirely pure life; we are all doomed to be sinners to some degree. Vegetarians, however, tend to see this in terms of drawing a line in terms of avoidance practices beyond which it is not reasonable to be expected to go.

\section{Drawing a Line}

Does this failure to avoid the use of leather suggest that the punctiliousness with which many vegetarians avoid such things as gelatine and rennet is connected with the fact that these things are ingested while leather is not, as the respondent quoted above suggests? Could it be that the apparent rules and observations relating to gelatine, rennet and other such substances, and also, therefore, refusing a meal containing meat, are less to do with maintaining a strict principle and observing rules of behaviour and more to do with feelings of contamination which do not arise in the case of leather and other products which are not ingested? The following interchange with the respondent quoted above, who justified using leather on the grounds that it was just a biproduct, suggests that some vegetarians are aware of and perhaps do accept such a possibility.

\section{Interviewer}

So it did bother you about the rennet from the stomach lining, because in a sense you could say that's sort of a byproduct.

\section{Respondent}

But it was still something that was going in me, in my body, from a living - should have been living - thing. You know, I am participating in its death if you like. That's how you felt.

\section{Interviewer}

But you think that you are participating more in its death by eating it than by using something that comes from it like leather?

\section{Respondent}

Probably not; probably there is no difference. I mean I know, you know, friends of mine would say there is no ...... difference, but to me there was a difference.

\section{Interviewer}

Yeah. But in a way you are saying that there was something about eating an animal, given your love of animals. 


\section{Food Science and Nutrition Technology}

\section{Respondent}

It's worse to actually consume it inside your own body. It was a very intimate thing, if you like. (SB8)

Respondents, for the most part, tended to perceive the potential contradiction in terms of drawing lines and recognising that there had to be limits somewhere beyond which they felt they could not be expected to go.

If you are wearing leather shoes, then you're not being consistent. You can't be consistent. It's not the sort of - you have to adopt a kind of pragmatic stance I suppose (SB18).

Yes the trouble is once you go down that way of thinking you can look at absolutely everything in your life and start relating it to the exploitation of animals and their death providing you with certain things. I feel that I have to draw the line somewhere but it is difficult. It is not something which I just dismiss but I think it does sound a bit hypocritical and contradictory but I won't buy myself a new leather coat but I would quite happily buy myself a leather coat from a second hand shop because I feel I am not providing the need for anything else to be killed if I am buying one that's already been used. Shoes are different. I am notoriously bad at buying myself shoes but I will buy our children shoes. Indeed a couple of days ago I bought two pairs of leather shoes. I guess it's ... as far as clothing is concerned it seems a more difficult decision to make because looking around there seem to be pieces of leather in an awful lot of clothing particularly shoes - even trainers. You have to have leather somewhere and I think it is all a question of conscience and doing your bit and trying to feel comfortable with yourself and I think I have a good balance. I still feel guilty at times if I bought something which was a leather product. (SB18)

Um, silk; I mean I can easily say well I don't wear silk. I wouldn't wear silk; it's rather cruel to the silkworms. But um, I do wear leather. Um, yeah, it's inconsistent but you draw lines. ....... can see the inconsistency but on the other hand, um, I, no - I don't know. It's just there's a slight inconsistency but if it seems - but the whole thing is inconsistent anyway because eating eggs is dependent on the meat industry - on the poultry industry - so the whole thing is slightly hypocritical but you do your best; you can't be perfect. (SB23)

The way society is you can't totally avoid animal products; for example, photography uses gelatine as a fixer. There are hundreds of things throughout the day which have an animal origin, you can't avoid. (VM3)
If one were to be 'fanatical', to use the word very commonly used by respondents themselves, one would have to eliminate all dairy products and eggs and adopt a vegan diet. This was regarded as simultaneously going too far - further than one should be reasonably expected to go - and also much too difficult. This is most clearly the case with regard to shoes. A number of respondents would avoid leather garments, bags etc but found it simply too difficult to do without leather shoes. The respondent previously quoted is a clear example. Another said.

It's one of those things I have thought of - have thought about - and I guess it's a flaw in my thinking really, or in my behaviour rather than thinking, but I do wear leather, leather shoes, but irrationally I suppose. I'll avoid buying, you know, I wouldn't buy a leather coat for instance. I suppose it's a question of practicality really and that's the measure of what I'm prepared to give up, I guess, for my principles. But I won't go out of my way to have something in leather. I won't have something in leather that doesn't need to be in leather. It's almost the sort of, the effort, of finding shoes that aren't leather. I mean there are shoes around that isn't leather, of course, but my conscience will buy that anyway. (LC2)

When faced with practical difficulties, then, even ethical vegetarians do not go all the way along the road of avoidance of animal products, either in terms of ingestion of them or in terms of external use. A possible justification for such consumption, and, as we have seen, one that is sometimes used, is that since these are only bi-products of meat production, consumption of them does not encourage meat production. While refusing to eat meat could conceivably reduce the demand for it and therefore the number of animals slaughtered, consuming the biproducts of the meat industry could not have any such effect. Also, while refusing a meal containing meat when invited to dinner might send an ethical message to others which could conceivably have some effect upon their behaviour in the future, avoiding products containing gelatine is very unlikely to do this. However, vegetarians are clearly not simply, or even primarily, motivated by the desire to reduce the number of animals slaughtered. Most respondents expressed no objection to others eating meat, were not in any sense crusading or critical in their attitudes to meat eaters and regarded the whole question as purely a matter of personal choice and conviction. The overwhelming view was that their vegetarianism was to do with their choice not to be involved or to participate in a practice which they felt to be unethical (or unhealthy). 


\section{Food Science and Nutrition Technology}

Most fully recognised that others did not share this point of view and could not, therefore, be judged in a negative way for their dietary preferences. Few respondents expressed any interest at all in attempting to convert them to their own ethical position.

It is ingestion, then, that seems to be more problematic. The line vegetarians nearly always have to draw which demarcates avoidance from use is more generally and easily drawn, it seems, between ingestion and external uses. Why is this so?

The reason vegetarians draw the line where they do draw it, namely between consuming meat derivatives as opposed to using the bi-products of meat production externally, is that most vegetarians and especially ethical vegetarians develop a very strong sense that meat is repugnant and disgusting. For most vegetarians far from having difficulty maintaining the rules of their diet they have the greatest difficulty in eating meat or anything derived from meat even in circumstances of social embarrassment arising from rejection of a meal containing meat. For most vegetarians, the refusal of a meal containing meat is not actually the consequence of firm observance of a rule and strong self-discipline in observing it despite the difficulties but of a profound repugnance at the very idea of ingesting meat or its derivatives.

But why should vegetarians be concerned to avoid consuming gelatine and rennet? Is this also because the idea of ingesting something of animal origin is repugnant whereas external use of something of such origin, as in the case of leather, is not? Inconsistent with such an interpretation is the fact that ingesting these products contained in foods is not quite the same thing as eating meat itself. It might be argued that the avoidance of such things by those vegetarians who do avoid them cannot be explained in terms of a dietary lifestyle in which observance of rules become important for its own sake or in terms of disgust and revulsion. After all, many vegetarians who do not, cannot, eat meat do consume gelatine and rennet either knowingly or inadvertently but without much concern. The point is, though, that observance and disgust explain why the intention of vegetarians is, generally, to avoid consumption of these things even if that intention is not always realized very punctiliously. Observance and disgust explain why the line of acceptability is drawn where it is, namely between ingestion and external use and not somewhere else. How careful vegetarians are to stay on the right side of this line in their actual behaviour is, indeed, quite variable.

\section{Conclusion}

In the light of the findings reported above, those aspects of vegetarian behaviour which seem difficult to understand may appear less so. Ethically motivated vegetarians have adopted a dietary stance and lifestyle which involves rules and observances the breach of which causes varying degrees of discomfort and sense of failure. They often find it difficult to follow the logic of their ethical stance through to its conclusion which might be veganism or even fruitarianism. No one can live a perfect and blame free life. A line must be drawn somewhere; somewhere reasonable. It tends to be drawn, at least ideally if not always in practice, between ingestion of animal products and their external use. This has the advantage of clarity even if it does not entirely satisfy in terms of logic or consistency within the terms of the ethical stance that such vegetarians adopt. The fact that it is drawn at this point reflects the deep repugnance that meat and meat derivatives have for ethically motivated vegetarians. There is something about ingesting meat and its derivatives that becomes abhorrent for many vegetarians. It is this that explains those aspects of vegetarian behaviour that often seem so difficult to make sense of, both to non-vegetarians and to vegetarians themselves, and which explains the place at which a line which defines acceptable and unacceptable practice is drawn.

The dilemmas that ethical vegetarianism poses occur, of course, in many circumstances where ethical principles guide behaviour or in any system of observances which constrain behaviour. Most commonly we think of systems of religious belief as being where such dilemmas arise. If it is wrong to take human life is this an absolute principle or is legitimate to sacrifice one life in order to save many? Under what conditions can an ethical or similar rule be broken? What counts as instance of breaching it? Does such a rule apply to a human foetus? At what stage of development is it a human life?

The main difference between such dilemmas and those posed by ethical vegetarianism are that for vegetarians the matter is almost entirely a personal one. There is no authority or community which expects or seeks to enforce conformity with the rule. Other circumstances in which this is true are such things as boycotts, purchase of fair trade commodities and ethical consumption generally. Increasingly in the contemporary world ethical concerns are of such a nature rather than stemming from allegiance to systems of belief and theologies of a more institutionalized kind. 


\section{Food Science and Nutrition Technology}

The findings described above may thus be generalisable to a range of behaviours motivated by ethical and quasi-ethical concerns in contemporary life. Rules and observances cannot be followed absolutely. A line has to be drawn somewhere and at the margins 'theological' deliberations are less significant than habit, awareness or the existence of a clear threshold or boundary such as ingestion. The equivalent of this in the case of abortion might be for some the point of conception or for others the point at which life is viable outside of the womb. In the case of vegetarianism and perhaps also for other cases this is reinforced by extraneous and emotional factors such feelings of disgust and repulsion.

In drawing a line, also, cost of observance is weighed against cost on non-observance. The wearing of leather shoes, for example, but not leather coats or use of leather handbags, is justified by many vegetarians in terms of necessity. Necessity outweighs the rule in the case of shoes. This is simply a matter of weighing the costs of observance against the desire to follow it. The cost of following it in the case of shoes is simply too great.

This is exactly what we should expect if we were to apply empirically that position in moral philosophy known as moral particularism(7). According to moral particularism moral reasons operate in much the same way as any other kind of reason. Moral reasons or principles do not over-rule in all circumstances other reasons for acting in a certain way. In other words moral particularism rejects the position in ethical philosophy that there are absolute principles of morality and also the position that while in any given situation there may be no over-riding moral principle that determines how one should act but several competing principles, moral action is determined by some balance of these principles. Moral particularism holds that what is a reason for acting in a certain way in one situation may not be a reason in another situation for acting in that way, whether these reasons are moral or non-moral reasons. For the moral particularist it may well be wrong to expect someone, for example, to act in accordance with a moral principle if they would incur great cost to themselves by doing so. It would all depend on the particular circumstances, how important the moral principles was, the effect of not meeting it, the cost to the person concerned of doing so, and so on. It is a matter of personal judgement as to what the right or acceptable course of action is, not a matter of absolute principles or even just of principles at all.

Ethical vegetarians, like all anyone else, may, in their everyday life behave as moral particularism predicts. They weigh all considerations and draw a line regarding conformity with the principles of their vegetarianism in places that seem reasonable to them, even though, as we have seen, they are uncertain and hesitant in their articulation of their reasons for and justification of their daily practice.

\section{Description}

${ }^{1} \mathrm{~A}$ telephone survey carried out in 1995 of 125 vegetarians in the Reading area found that a clear majority (approximately 70 per cent) of those who abstained from eating meat but ate fish identified themselves as vegetarian.

${ }^{2}$ Those brought up vegetarian are all counted as having added one or more motives to their original 'motive'. In all but one case of a respondent who disliked meat they had come to adopt an ethical stance on meat eating.

${ }^{3}$ The two lapsed vegetarians are, of course, not included here.

${ }^{4}$ For purposes of comparison of ethically motivated and health motivated vegetarians respondents whose stated original motivation included both ethical and health considerations are excluded. The ethical category thus includes all those respondents who stated that morality was the sole primary original motivation plus all those who combined an ethical motivation with some other as long as this was neither health nor dislike of meat nor any other motivation such as economic, convenience, environmental etc. Similarly, the health category in these comparisons includes all those who stated health as the sole primary original motivation plus all those who combined health with some other motivation as long as this was neither ethical nor dislike of meat nor any other motivation. This reduces the total number in each category in the ethical/health comparisons to 17 and 10 respectively. Six respondents stated both ethical and health reasons for their original adoption of a vegetarian diet. Five stated dislike of meat but neither ethical nor health motives and these were placed in a separate category whether or not they combined dislike with any other motive other than ethical or health concerns. Finally, eight respondents stated other motives not including ethical, health or dislike.

${ }^{5}$ This rather high figure leads Willetts to challenge the notion of a distinct vegetarian diet as opposed to a meat eating diet. This goes rather too far and is not really warranted by her data. The number of self-reported vegetarians in the sample was only 17 . They were not recruited as vegetarians but were part of a larger sample of the population of the area who defined themselves as vegetarian. It is not uncommon for people to use this term rather vaguely and loosely today to suggest that they consume little meat rather than necessarily indicating a 


\section{Food Science and Nutrition Technology}

dietary practice in accordance with ethical principles, health or environmental concerns. Also, Willetts does not tell us how many of these 17 were ethically motivated. It is ethically motivated vegetarians who tend to be more strict about avoiding all meat and meat products in their diet.

${ }^{6}$ Worsley and Skrzypiec (1998) argue that the motive if radicalism and rebellion is largely a feature of teenage rather rather than adult vegetarianism.

${ }^{7}$ For an account of moral particularism see McNaughton, 1988., chapter 13.

\section{References}

1. Beardsworth AD, Keil ET (1992) The vegetarian option: varieties, conversions, motives and careers. Sociological Review 40 (2) 253-293.

2. Willetts A (1997) Bacon sandwiches got the better of me": meat eating and vegetarianism in South East London. In P. Caplan (Ed.) Food, health and identity. London: Routledge.

3. Amato PR, Partridge SA (1989) The new vegetarians: promoting health and preserving life. New York: Plenum Press.
4. Beardsworth AD, Keil ET (1993) Contemporary vegetarianism in the UK: Challenge and incorporation? Appetite 20(3): 229-234.

5. Rozin P, Markwith M, Stoess C (1997) Moralizing and becoming a vegetarian: the transformation of preferences and the recruitment of disgust. Psychological Science 8(2): 67-73.

6. Mac Nair RM (1998) The psychology of becoming a vegetarian. Vegetarian Nutrition 2(3): 96-102.

7. O'Toole R (1977) The precipitous path: studies in political sects. Toronto: Peter Martin.

8. Twigg J (1983) Vegetarianism and the meaning of meat. In A. Murcott (Ed.), The sociology of food and eating. Aldershot: Gower.

9. McNaughton D (1988) Moral Vision: An Introduction to Ethics. Oxford: Blackwell, pp: 2014.

10. Worsley A, Skrzypiec G (1998) Teenage vegetarianism: prevalence, social and cognitive contexts. Appetite 30(2): 151-70. 